\title{
AETIOLOGICAL AND CLINICAL PROFILE OF ACUTE MYELOID LEUKAEMIA IN A TERTIARY CARE HOSPITAL
}

Mohamed Shaan1, Anza Khader ${ }^{2}$

${ }_{1}^{1}$ Associate Professor, Department of General Medicine, Government Medical College, Kozhikode, Kerala.

${ }^{2}$ Associate Professor, Department of Dermatology, Government Medical College, Kozhikode, Kerala.

\section{BACKGROUND}

ABSTRACT

Acute myeloid leukaemia (AML) is a group of neoplastic disorders characterised by the proliferation and accumulation of immature haematopoietic cells in the bone marrow and blood. It is the most common type of leukaemia among adults. The underlying pathophysiology in AML consists of a maturational arrest of bone marrow cells in the early stages of development.

Aims and Objectives- To look for the possible aetiological factors in patients with Acute Myeloid Leukaemia and to study the clinical profile and to determine any prognostic factors with the help of clinical parameters and basic investigations.

\section{MATERIALS AND METHODS}

All patients above 12 years of age with acute myeloid leukaemia admitted in haematology unit of Department of Medicine between July 2009 and June 2013 were included in the study. The diagnosis of AML with subtypes was established based on clinical features, peripheral smear and bone marrow findings.

\section{RESULTS}

There were 100 patients ( 47 males, 53 females). Amongst aetiological factors, cigarette smoking was most commonly seen. Easy fatigability was the commonest presenting symptom, followed by fever, anorexia, weight loss and bleeding. The most common clinical finding was pallor followed by wet purpura, generalised lymphadenopathy and gum hypertrophy. The mean haemoglobin value was $7.35 \mathrm{gm} \%$ and platelet count was 56,740 cells $/ \mathrm{mm}^{3}$. WBC count varied between $600 \mathrm{cells} / \mathrm{mm}^{3}$ and 2,61,000 cells $/ \mathrm{mm}^{3}$. Among the subtypes of AML, most common leukaemia was AML M2 followed by AML M3.

\section{CONCLUSION}

Easy fatigability and malaise were the most common presentations in AML. Environmental factors like anti-cancer drug exposure, chemical exposure, smoking, proximity to mobile towers, high tension electric lines and dietary factors like poor intake of vegetables and fruits may have an influence on aetiopathogenesis of AML. Very high WBC count, bleeding manifestations and platelet count at presentation $<20,000 / \mathrm{mm}^{3}$ all had a poor outcome. AML M2 was the most common subtype followed by AML M4, the prognosis was best in AML M2 and M3.

\section{KEY WORDS}

Acute Myeloid Leukaemia, AML M2.

HOW TO CITE THIS ARTICLE: Shaan M, Khader A. Aetiological and clinical profile of acute myeloid leukaemia in a tertiary care hospital. J. Evolution Med. Dent. Sci. 2018;7(21):2566-2571, DOI: 10.14260/jemds/2018/578

\section{BACKGROUND}

Acute myeloid leukaemia (AML) is a group of neoplastic disorders characterised by the proliferation and accumulation of immature haematopoietic cells in the bone marrow and blood. It is the most common type of leukaemia among adults. The underlying pathophysiology in AML consists of a maturational arrest of bone marrow cells in the early stages of development.

'Financial or Other Competing Interest': None.

Submission 10-04-2018, Peer Review 05-05-2018,

Acceptance 11-05-2018, Published 21-05-2018.

Corresponding Author:

Dr. Anza Khader,

Associate Professor,

Department of Dermatology,

Government Medical College,

Kozhikode,

Maskan, 5/1986 B, KP Chandran Road,

PO-Puthiyara, Calicut-673004, Kerala.

E-mail: anzashaan@gmail.com

DOI: $10.14260 /$ jemds $/ 2018 / 578$
Exposure to radiation, chronic exposure to high doses of benzene and chronic heavy inhalation of tobacco smoke is associated with increased incidence of the disease. ${ }^{1} \mathrm{AML}$ is in general a disease of the older age group. The median age of incidence is around 65 yrs. in various studies. ${ }^{2,3,4}$

\section{Aims and Objectives}

1. To look for the possible aetiological factors in patients with Acute Myeloid Leukaemia.

2. To study the clinical profile of patients with Acute Myeloid Leukaemia.

3. To determine prognostic factors with the help of clinical parameters and basic investigations.

\section{MATERIALS AND METHODS}

Study Design

Observational study.

\section{Period}

4 years (July 2009 - June 2013). 


\section{Centre}

Haematology Unit, Department of Medicine (Ward 2/ 31), Government Medical College, Kozhikode.

\section{Sample Size}

100 patients.

\section{Inclusion Criteria}

All patients above the age of 12 years with Acute Myeloid Leukaemia, admitted in Haematology Unit of Department of Medicine.

\section{Exclusion Criteria}

1. Seriously ill patients with acute myeloid leukaemia.

2. Patients who have not given the consent to be a part of the study.

\section{Methods}

A detailed history and physical examination along with relevant investigations were done in all the patients after obtaining their consent. A detailed history was taken to elucidate aetiological factors like chemical exposure and proximity of residence to high tension electric lines, mobile towers and addictions. A meticulous dietetic history was taken in order to know the influence of various dietary habits and food faddism with respect to acute myeloid leukaemia. All the patients underwent thorough clinical examination and investigations including blood routine, renal function tests, liver functions, random blood sugar, uric acid and serum electrolytes were done. Imaging modalities including ultrasonography of abdomen and computed tomography of head were done only in selected group of patients to rule out any complications.

The diagnosis of AML with subtypes was established based on clinical features, peripheral smear and bone marrow findings. Flow cytometry was done in only five patients and could not be done in others due to financial constraints.

The prognostic markers were deduced from their clinical parameters, mode of onset, duration of illness, co-morbid conditions, basic investigations, complications, presence of various clinical signs like organomegaly, bleeding tendency or any other new symptom or sign which appeared during the course of study.

The results were entered into a Microsoft Excel sheet and then analysed using the SPSS statistical software version 20 and conclusions drawn accordingly. The statistical significance of different variables was calculated on the basis of Chi-square test.

\section{RESULTS}

A total of 100 cases of Acute Myeloid Leukaemia were included in the study.

\section{Age Distribution}

The mean age was 43 yrs. The youngest affected was 14 years of age and oldest was 87 years old. A majority of $67 \%$ of patients were less than 50 years (Figure 1). The relationship between age and mortality has been depicted in Table 1 .

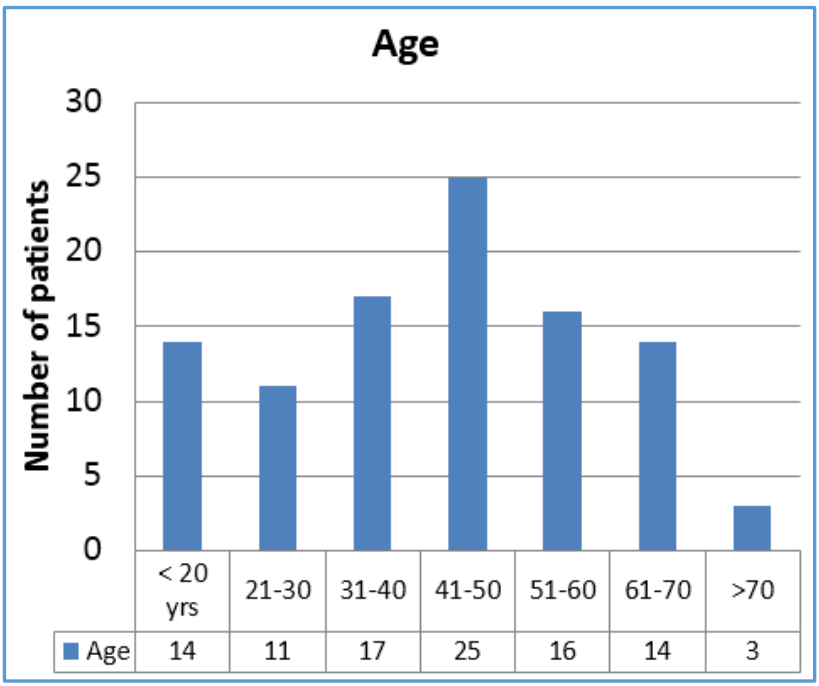

Figure 1. Age distribution in the Study Population

\begin{tabular}{|c|c|c|}
\hline Age & Death- N (\%) & Alive- N (\%) \\
\hline Less than 20 & $9(69.2)$ & $4(30.8)$ \\
\hline $20-39$ & $19(76)$ & $6(24)$ \\
\hline $40-59$ & $34(87.2)$ & $5(12.8)$ \\
\hline 60 and above & $23(100)$ & $0(0)$ \\
\hline \multicolumn{3}{|c|}{ Table 1. Age and Mortality } \\
\hline
\end{tabular}

p-value: 0.04

\section{Gender Distribution}

In the study group, 47 were males and 53 were females. Male: Female ratio was 0.88: 1 (Figure 2). Relationship between sex and mortality rate is shown in Table 2 .

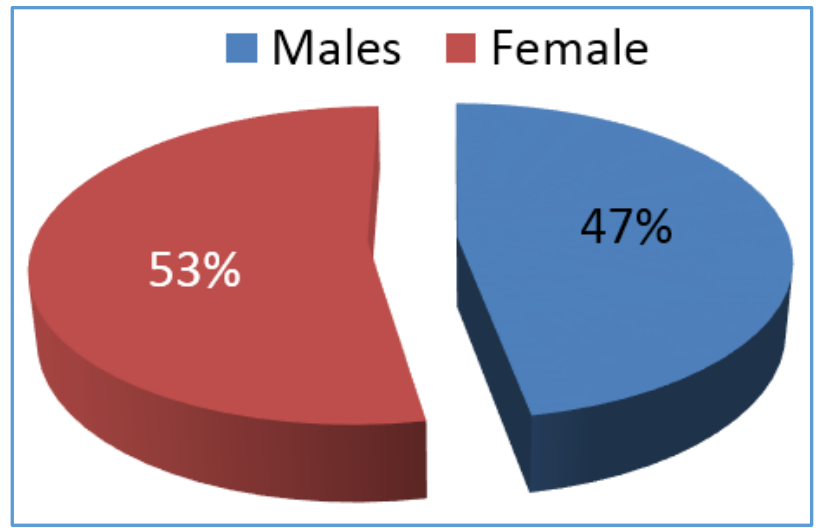

Figure 2. Gender distribution in the Study Population

\begin{tabular}{|c|c|c|}
\hline Sex & Death- N (\%) & Alive- N (\%) \\
\hline Female & $45(84.9)$ & $8(15.1)$ \\
\hline Male & $40(85.1)$ & $7(14.9)$ \\
\hline \multicolumn{3}{|c|}{ Table 2. Sex and Mortality } \\
\hline
\end{tabular}

p-value: 0.978

\section{Education}

Of the study population $44 \%$ had primary schooling, $51 \%$ had secondary schooling and $5 \%$ were graduates.

\section{Occupation}

A majority of 45 patients were manual labourers, 38 were housewives, 5 were working as office staff and 12 were students. 


\section{Income}

There were 78 patients who belonged to below poverty line group and 22 were above poverty line.

\section{Place of Residence}

There were 38 patients each from Kozhikode and Malappuram district. Eleven patients were from Wayanad and nine patients came from Kannur district. One patient came from Tamilnadu and there were two patients from Palaghat district.

\section{Possible Aetiological Factors}

Addiction to various substances, exposure to toxins, pesticide and radiations, proximity to any source of radiation including mobile towers etc. were studied. The following table depicts incidence of those factors (Table 3).

\begin{tabular}{|c|c|}
\hline Probable Risk Factor & $\begin{array}{c}\text { Incidence among } \\
\text { Study Population }\end{array}$ \\
\hline Smoking cigarettes and beedi & $30 \%$ \\
\hline $\begin{array}{c}\text { Chemical exposure (pesticides and } \\
\text { petroleum products) }\end{array}$ & $9 \%$ \\
\hline $\begin{array}{c}\text { Proximity to high tension lines and } \\
\text { mobile tower }\end{array}$ & $8 \%$ \\
\hline $\begin{array}{c}\text { Treatment with other modalities for } \\
\text { prolonged period (> 10 years) }\end{array}$ & $7 \%$ \\
\hline Pan chewing & $5 \%$ \\
\hline Alcoholism & $2 \%$ \\
\hline Prior anti-cancer treatment & Table 3 \\
\hline \multicolumn{2}{|c|}{} \\
\hline
\end{tabular}

\section{Dietary Habits}

The dietary pattern observed among patients was that about 35 patients were in habit of taking a predominantly nonvegetarian diet, whereas 65 patients were predominantly vegetarian. Among 35 patients who took predominantly nonvegetarian diet had habit of eating fried food items almost daily and all of them took an unbalanced diet with very little fruits and vegetables in their daily diet.

\section{Family History}

No family history of consanguinity was noted in any of the patients. But there was history of malignancy in the family in seventeen of the patients. Among them in nine of the patients, there was history of malignancy in their parents, predominantly pertaining to gastrointestinal system including Ca stomach, Ca colon and Ca oral cavity. In seven of the AML patients, positive family history of malignancy were seen in siblings. Among the seven patients, two had family history of haematological malignancy.

\section{Addictions}

Addiction to smoking was seen in 30 patients. Five had alcohol addiction in addition to smoking. Betel leaf and tobacco chewing was seen in 6 cases. No cases of substance abuse were found in the study group.
BMI

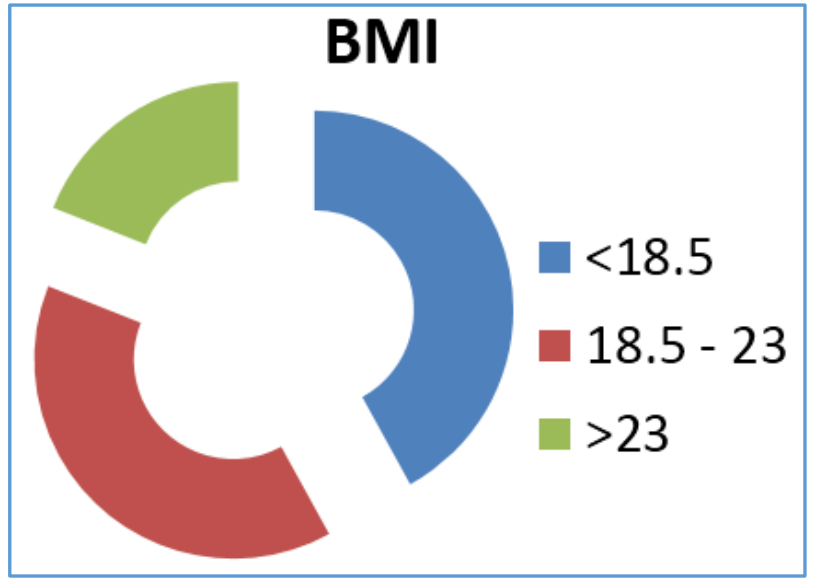

Figure 3. Distribution of BMI in Study Population

A majority of forty-two patients had a BMI < 18.5, 39 patients had BMI between 18.6-23 and 19 patients had BMI > 23. Lowest BMI noted was about 14 and highest one seen was 32 (Figure 3).

\section{Clinical Presentation}

Easy fatigability was the commonest presenting symptom seen in 81 cases followed by fever, which was seen in 75 of cases. Anorexia was seen in 63 patients, whereas significant weight loss was observed in 55 patients. Bleeding manifestations was seen in 45 of patients. In females, the predominant form of bleeding was menorrhagia. Other forms of bleeding such as oral bleed, epistaxis and subconjunctival haemorrhage were also seen. Dyspnoea on exertion was yet another major symptom seen in 19 patients.

Gum hypertrophy was a prominent finding in about 25 patients. As seen in all previous studies, it is most commonly associated with monocytic leukaemic variant (5 patients were M4 type and four patients had M5 type of AML). One interesting observation which could be made was that it was also seen in AML-M3 (5 patients), AML-M1 (4 patients), AMLM2 (3 patients) and AML-M6 (2 patients). The presence of gum hypertrophy is thus evenly distributed in all subsets of AML.

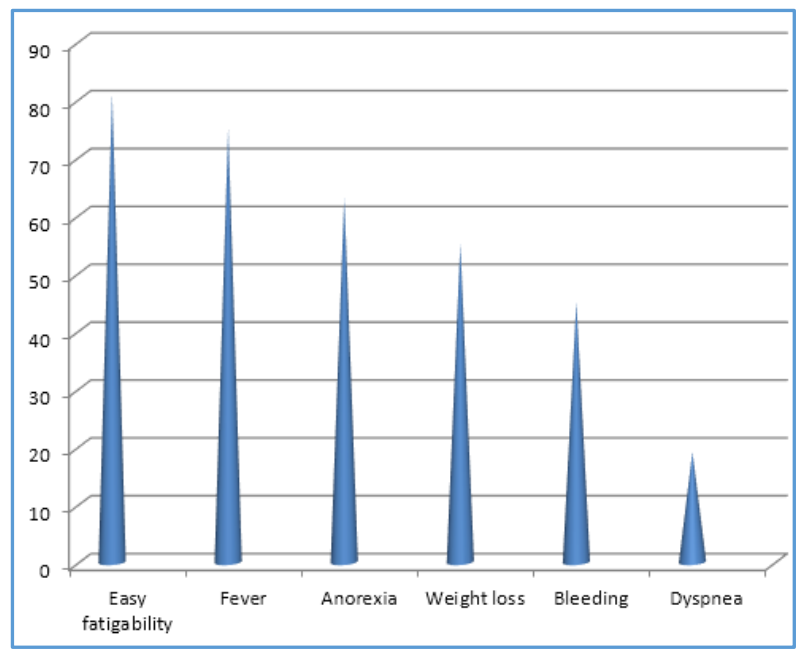

Figure 4. Clinical Presentations 
On clinical examination pallor was seen in 89 patients, signs of bleeding including petechiae, oral bleeds were seen among 41 patients and lymph node enlargement was seen in 25 patients. Clubbing was seen among nine of the patients.

\section{Haemoglobin Values}

Haemoglobin value between 7 - 12 gm $\%$ was seen in $50 \%$ of patients and $40 \%$ of patients had a value between $4-7 \mathrm{gm} \%$. The highest value noted was $17.3 \mathrm{gm} \%$ and lowest value was 3 gm\%. Relationship between haemoglobin values and mortality has been depicted in Table 4 .

\begin{tabular}{|c|c|c|}
\hline Haemoglobin (gm\%) & Death- N (\%) & Alive- N (\%) \\
\hline Less than 6 & $22(88)$ & $3(12)$ \\
\hline $6-7.9$ & 35 (89.7) & $4(10.3)$ \\
\hline $8-9.9$ & $18(78.3)$ & $5(21.7)$ \\
\hline $10-11.9$ & $6(66.7)$ & $3(33.3)$ \\
\hline More than 12 & $4(100)$ & $0(0)$ \\
\hline
\end{tabular}

(p-value 0.3)

\section{White Blood Cell Counts}

WBC count $<1,000$ was seen only in 4 patients and 10 patients had WBC counts more than one lakh. Only 22 patients had counts within normal range (4000-11000 cells $/ \mathrm{mm}^{3}$ ). The lowest count seen was 600 cells $/ \mathrm{mm}^{3}$ and highest one was 2,61,000 cells $/ \mathrm{mm}^{3}$ (Figure 11). The relationship between total WBC count and mortality has been shown in Table 5.

\begin{tabular}{|c|c|c|}
\hline $\begin{array}{c}\text { Total WBC Count } \\
\text { (cells/mm3) }\end{array}$ & Death- N (\%) & Alive- N (\%) \\
\hline Less than 6000 & $30(76.9)$ & $9(23.1)$ \\
\hline $6000-10,999$ & $12(85.7)$ & $2(14.3)$ \\
\hline More than 11,000 & $43(91.5)$ & $4(8.5)$ \\
\hline \multicolumn{2}{|c|}{ Table 5. Total WBC Count and Mortality } \\
\hline
\end{tabular}

p-value: 0.169 .

\section{Platelet Counts}

Majority of the patients, $72 \%$ had platelet counts between $10,000-1$ Lakh and ten patients had very low count of less than 10,000 . Only ten patients had a normal platelet count. Lowest count was 1000 and highest value was 3.4 lacks cells $/ \mathrm{mm}^{3}$. The relationship between platelet count and mortality is shown in Table 6.

\begin{tabular}{|c|c|c|}
\hline $\begin{array}{c}\text { Platelet Count } \\
\text { (lacks/mm3) }\end{array}$ & Death- N (\%) & Alive- N (\%) \\
\hline More than 1.5 & $8(88.9)$ & $1(11.1)$ \\
\hline $1-1.49$ & $9(90)$ & $1(10)$ \\
\hline $0.5-0.99$ & $22(91.7)$ & $2(8.3)$ \\
\hline $0.25-0.49$ & $20(80)$ & $5(20)$ \\
\hline Less than 0.25 & $26(81.3)$ & $6(18.8)$ \\
\hline \multicolumn{2}{|c|}{ Table 6. Platelet Count and Mortality } \\
\hline
\end{tabular}

p-value: 0.739

\section{Other Investigations}

Erythrocyte sedimentation rate (ESR) was increased in all the patients with 52 patients having significant ESR more than 100 (highest being $182 \mathrm{~mm} / 1^{\text {st }}$ hour). Renal function tests were abnormal in five of patients with both blood urea and serum creatinine being elevated before initiating chemotherapy. Seven patients had liver function abnormality with high bilirubin and mild elevation of SGPT. Almost, fourteen patients had hypoalbuminaemia.

\section{Blood Group}

Most common blood group seen was 0 positive in $43 \%$ of patients followed by B positive (30\%) and A positive (16\%). $O$ negative and $A B$ negative groups were seen in one patient each (Figure 5).

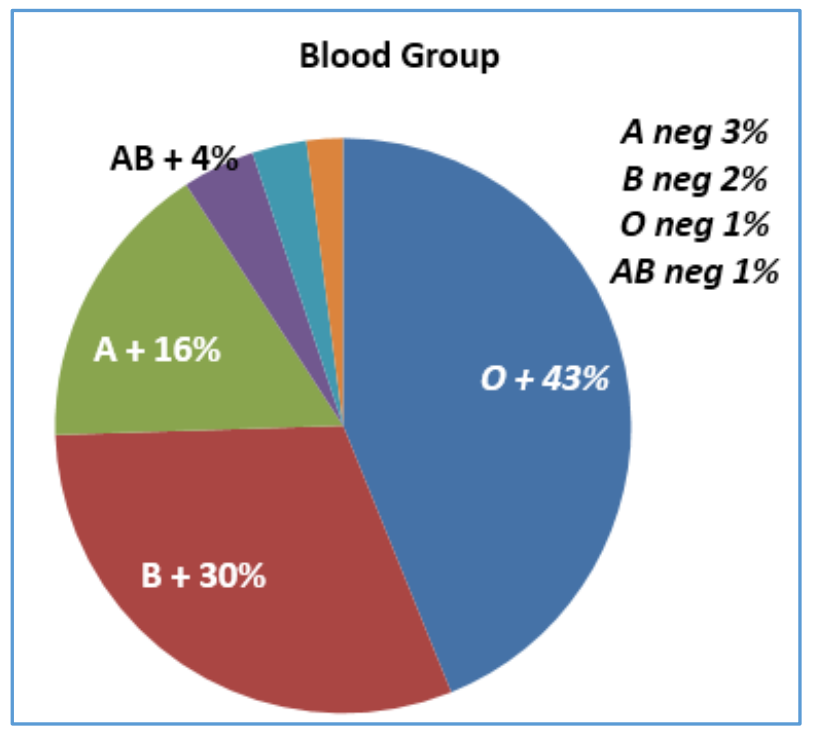

Figure 5. Distribution of Blood Groups in the Population

\section{AML Subtypes}

AML subtype distribution in the study is shown in Fig. 6. A slight predominance of AML- M2 was noted followed by AML- M3.

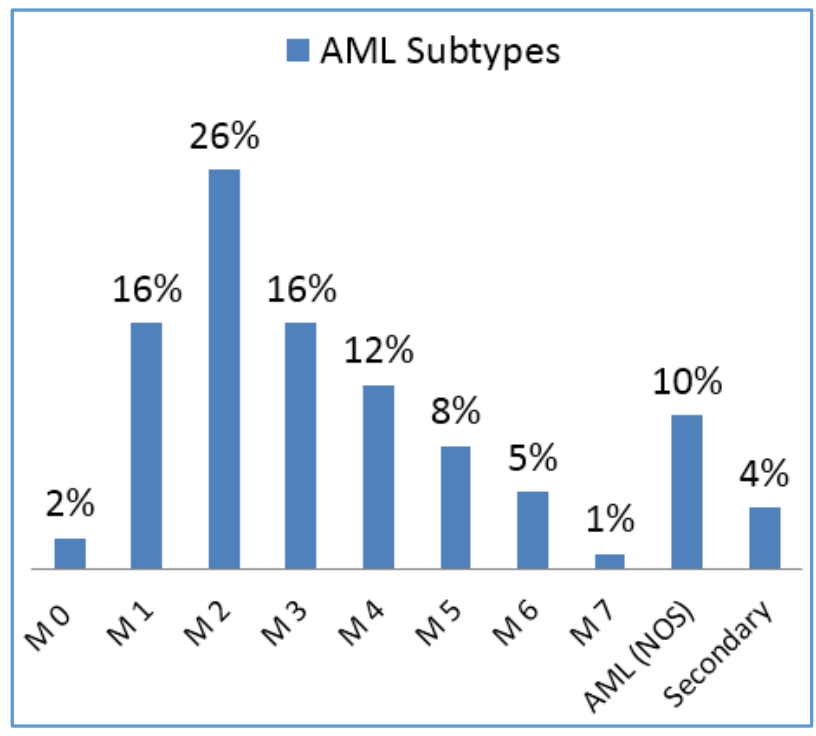

Figure 6. AML Subtypes

Flow cytometry could be done in only five cases, where it was not possible to arrive at a diagnosis by morphology alone. Co-expression of CD34 was seen in five cases. There were altogether sixteen patients of AML- M3. Eight of them were diagnosed with peripheral smear itself, rest of eight patients were found out after bone marrow examination only. 
Among the patients with AML- M3, only 10 patients had PML RAR alpha (promyelocytic retinoic acid receptor) positivity.

\section{DISCUSSION}

Acute myeloid leukaemia is generally considered a disease of older age group with median age of 65 yrs. ${ }^{5}$ In our study, 67 patients were less than 50 yrs. and 25 patients were less than 30 yrs. However, Mehta et al has reported a median age of 30 yrs. in studies from India. ${ }^{6}$ The median age was found to be less in our study. This may be because of early occurrence of malignancies, which could be related to poor nutritional status and lower socioeconomic status of patients studied.

Regarding gender distribution, it is usually more common in males. A study from US shows that the male: female ratio is approximately 5: 3.7 In our study, it was found that male:female ratio was almost the same and the cause of which cannot be commented due to the fewer number of cases.

Among the study population, $56 \%$ had better educational status $(51 \%$ had secondary schooling and $5 \%$ with graduation), which reflects the overall educational level of the state. This implies the ability of patient to understand the nature of the disease and prognosis and hence had better compliance with therapy.

Among the hundred patients, majority were manual labourers. In our study, 78 patients belonged to below poverty line group and only 22 were above poverty line. As a result, it was difficult to give aggressive treatment schedule in view of the high cost. Even though it was a limitation of our study, this limitation was helpful in comparing the palliative protocol in more number of patients versus aggressive treatment plan.

We made an attempt to find out any other dietary or environmental factor which predisposes to leukaemias. Diet has been implicated among the aetiological factors in many studies. ${ }^{8}$ The dietary pattern observed among patients in our study was that about 35 patients were in habit of taking a predominantly non-vegetarian diet, whereas the rest 65 patients were predominantly vegetarian with poor intake of fruits in their daily diet. A definite conclusion cannot be drawn based on above observation, as there was no proper control group. There are various unidentified factors in the diet, which may predispose to molecular and chromosomal aberrations leading to leukaemogenesis. Therefore, it is not a single risk factor, but it may be one of the risk factors which may predispose to leukaemia. There will be multiple factors in combination including radiation, toxins, chemicals and infections, genetic and dietetic factors which may predispose to the disease.

Environmental factors and leukaemia has been extensively studied with many positive and sometimes controversial results. Chemical exposures to pesticides were noted in only $9 \%$ cases, but almost the same was seen in $5 \%$ of relatives of the patients. So significance of the same cannot be derived unless it is studied with a larger number of patients.

Proximity of residence to high tension lines has been implicated in aetiology. These have been shown to produce alternating magnetic fields and thus physiological alterations. ${ }^{9}$ It was identified in our study in $8 \%$ cases. The presence of high tension lines within 200 meters of residence was taken as significant exposure in the present study. In our study, no significant radiation exposure was identified among the cases.

Exposure to chemotherapeutic agents has been identified as a risk factor. ${ }^{10}$ We had 2 patients in our group of 100 , who had history of prior chemotherapy. One patient who had treatment for breast cancer developed therapy related AML five years after chemotherapy. The other patient was a male with AML- M3 who was treated with Arsenic trioxide in 2007 who relapsed after a period of six years as AML- M1. Exposure to chemotherapeutic agent as a risk factor for leukaemia was not found to be significant in our study.

Smoking had been identified as a risk factor in various studies. ${ }^{11}$ In our study, smoking was identified in $30 \%$ of the cases. Habit of pan chewing was seen in about $6 \%$ of patients and alcoholism was seen in $5 \%$ of study population. None of the addictions had a definite statistical significance. The presence of malignancy in the family of seventeen patients could be attributed to same environmental exposure and dietary habits.

The clinical presentations of patients were varied, but the most common presenting complaint was easy fatigability seen in $81 \%$ cases followed by fever and anorexia. This observation is well in keeping with previous studies on the subject. ${ }^{5}$ Fever as a presenting symptom has been noted in $10-20 \%$ cases in various studies, but in our study, it came to $75 \%$ which was in concordance with an Indian study done by Mehta et al.

In our study, bleeding manifestations were noted in $45 \%$ cases which was already reported in various other studies where it ranges from $20-50 \% .^{6}$ In a study by Salim KA et al, bleeding manifestations were seen in $30 \%$.

Other associated complaints included abdominal fullness with no significant organomegaly, non-specific cough, diaphoresis and loss of weight. It is necessary to have a high index of suspicion when a patient presents with non-specific complaints, lest the diagnosis be delayed and hence deteriorating the outcome.

On clinical examination, pallor was commonest sign followed by lymph node enlargement. Gum hypertrophy was a prominent finding in all subsets of AML and most commonly associated with monocytic leukaemic variant M4 and M5. It probably indicates the poor dental hygiene that is present in our patients. Moreover, poor oral hygiene has greater implication, especially with respect to infective complications during chemotherapy. Such patients are more prone for severe oral bleed.

Anaemia was seen in almost $96 \%$ cases, but significant anaemia- moderate and severe, as per WHO definition, were found in $46 \%$ cases. No significant association between low haemoglobin and treatment outcome could be found out ( $\mathrm{p}$ value 0.27 ).

WBC count has been proposed and used as a prognostic marker for long. ${ }^{12}$ In our study, 4 patients having a count $<1,000$ where $76 \%$ of patients had a very high total WBC count and ten patients had WBC count more than one $\mathrm{lac} / \mathrm{mm}^{3}$ and they were found to have poor treatment outcome.

Platelet count had been found to have a significant predictive value in our study. Very low platelet count had high rate of mortality where $87.5 \%$ of patients with less than $20,000 / \mu \mathrm{L}$ died (p-value was 0.02). 


\section{CONCLUSION}

1. Easy fatigability and malaise were the most common presentations in AML.

2. Environmental factors like anti-cancer drug exposure, chemical exposure, smoking, proximity to mobile towers, high tension electric lines and dietary factors like poor intake of vegetables and fruits may have an influence on aetiopathogenesis of AML.

3. To predict the outcome of chemotherapy, clinical prognosticators have been useful. Very high WBC count, bleeding manifestations and platelet count at presentation $<20,000 / \mathrm{mm}^{3}$ all had a poor outcome.

4. AML- M2 was the most common subtype followed by AML- M4, the prognosis was best in AML- M2 and M3.

\section{REFERENCES}

[1] Sandler DP, Ross JA. Epidemiology of acute leukemia in children and adults. Semin Oncol 1997;24(1):3-16.

[2] Linet MS, Devesa SS. Epidemiology of leukemia: overview and patterns of occurrence. In: Henderson ES, Lister TA, Greaves MF, eds. Leukemia. Philadelphia: WB Saunders 2002: p. 131-51.

[3] Deschler B, Lubbert M. Acute myeloid leukemia: epidemiology and etiology. Cancer 2006;107(9):2099107.

[4] Ries LAG, Melbert D, Krapcho M, et al. SEER cancer statistics review, 1975-2004, National Cancer Institute. Bethesda, MD, based on November 2006 SEER data submission, posted to the SEER Web site, 2007. http://seer.cancer. gov/csr/1975_2004
[5] Baer MR, Greer JP, Kinney MC. Acute myeloid leukemia in adults. Chap - 79. Wintrobe's clinical hematology. Vol. 2. 12 $2^{\text {th }}$ edn. Williams \& Wilkins 2009: p. 1844.

[6] Mehta J, Powles R, Treleaven J, et al. The impact of karyotype on remission rates in adult patients with de novo acute myeloid leukemia receiving high-dose cytarabine-based induction chemotherapy. Leuk Lymphoma 1999;34(5-6):553-60.

[7] Mosler F. Klinische Symptome and Therapie des medullaren Leukamia. Berliner Klin Wschr 1876: p. 702.

[8] World Cancer Res Fund Panel. Food, nutrition and the prevention of cancer: a global perspective. American Institute for Cancer Res. Washington, DC: 1997.

[9] Doll R. Cancers weakly related to smoking. Br Med Bull 1996;52(1):35-49.

[10] Garfinkel L, Boffetta P. Association between smoking and leukemia in two American Cancer Society prospective studies. Cancer 1990;65(10):2356-60.

[11] Boice JD Jr. Radiation-induced leukemia. In: Henderson ES, Lister TA, Greaves MF, eds. Leukemia. Philadelphia: WB Saunders 2002: p. 152-69.

[12] Liu CY, Hsu YH, Wu MT, et al. Cured meat, vegetables and bean-curd foods in relation to childhood acute leukemia risk: a population based case-control study. BMC Cancer 2009;9:15. 